\title{
Laborer Dies When Caught in Arms of a Skidsteer Loader Incident Number: 03KY087
}

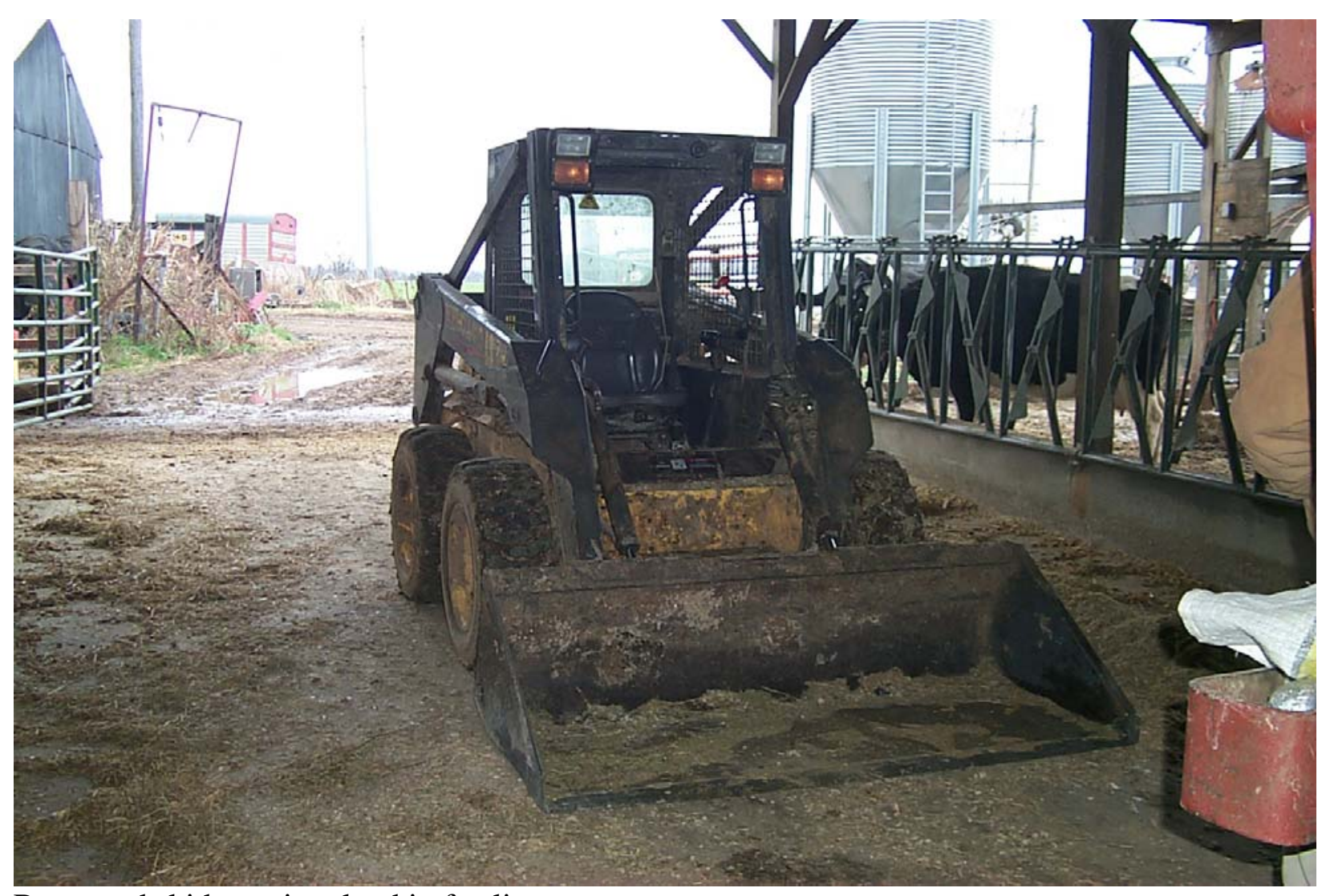

Borrowed skidsteer involved in fatality.

Kentucky Fatality Assessment and Control Evaluation Program Kentucky Injury Prevention and Research Center 333 Waller Avenue Suite 202

Lexington, Kentucky 40504

Phone: 859-323-2981

Fax: 859-257-3909

www.kiprc.uky.edu

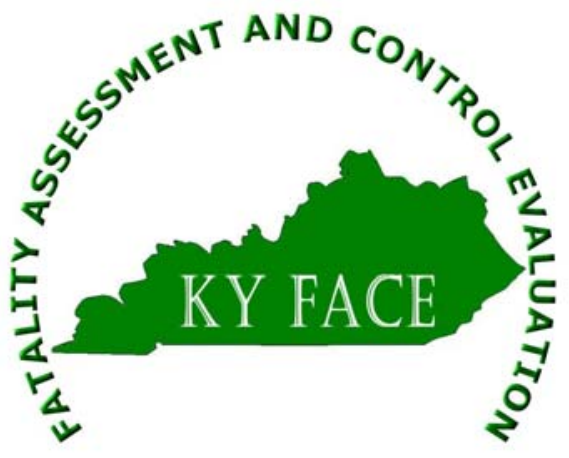




\section{Kentucky Fatality Assessment and Control Evaluation (FACE) Program Incident Number: $\quad$ 03KY087 Incident Date: $\quad$ September 19, 2003 Release Date: $\quad$ November 5, 2004 Subject:

\author{
Laborer Dies When Caught in Arms of a \\ Skidsteer Loader
}

\section{Summary}

On September 19, 2003, a 23-year-old male laborer (decedent) died when he became caught in the activated arms of a skidsteer loader. A work crew consisting of a contractor and 3 laborers had spent the day installing fence on a dairy farm. Earlier in the day, the contractor had borrowed a skidsteer from the farm owner. The work crew used the skidsteer to set fence posts in the ground. At the end of the work day (approximately 4:00 PM), the contractor instructed the decedent to return the skidsteer to the barn area. From the work site, the decedent drove the skidsteer 200 yards with the bucket in the upright position (above the cab of the machine) to the gate for the barn area. As the decedent approached the gate and stopped the machine, the decedent kept the arms of the skidsteer in the upright position. The exact circumstances of what happened next are unknown. No one saw the decedent exit the machine to open the gate. The contractor (200 yards away with the other laborers) heard the machine idle but not moving, looked over and saw the decedent trapped between the arms and the machine. Upon seeing the trapped decedent, the contractor and the other two laborers ran the 200 yards to the skidsteer. The dairy farmer noticed the situation and also ran to the skidsteer. When the contractor, laborers and dairy farmer arrived at the skidsteer, they found the decedent caught in between the arms and the body of the machine and removed the decedent's body from the machine. Emergency services were contacted. When emergency services arrived several minutes later, the laborer was determined to be dead and the coroner was contacted. The coroner arrived and pronounced the victim dead at the scene.

To prevent future occurrences of similar incidents, the following recommendations have been made:

Recommendation No. 1: Employers should ensure that employees are adequately trained on proper operation of and safety mechanisms of material handling equipment.

Recommendation No. 2: Employers should have a written safety policy outlining safety practices and procedures. This policy should state the consequences of not following the company policies (1).

\section{Background}

On November 3, 2003, the Kentucky Fatality Assessment Control and Evaluation program was notified of an occupational fatality on a farm involving a skidsteer. A site visit was made on November 11, 2003 when the farmer and coroner were interviewed. The Kentucky Occupational Safety and Health administration representative was also interviewed. 
On September 17, 2003, a contractor and 3 laborers were repairing and installing fence for a dairy farmer. The contractor had previously worked for the dairy farmer installing and repairing fence at different locations on the same farm. On the day of the incident, the contractor borrowed a 2001 model skidsteer from the farmer to help drive fence posts. The contractor owned and operated an identical skidsteer which he and the decedent had used on other fencing job sites. Purchased new by the farmer in 2001, the skidsteer had logged 1466 hours at the time of the incident. The skidsteer loader was used to feed livestock twice a day, clean the feed lot and assume other projects around the farm. Routine maintenance on the machine was performed on a regular schedule by the farmer.

This particular model of skidsteer loader has several safety features: 1) the machine will not start if the safety belt is not fastened; 2) when the driver leaves the seat, the machine locks up, (i.e., if the arms are moving and the driver leaves the seat, the arms will stop moving); and 3) there is a dial on the seat to set operator weight in order to lock out controls. For example, the weight could be set at 160 pounds. Therefore, the seat has to have at least 160 pounds of pressure on it before it will start. This would keep a child from being able to start the machine. The farmer did not know what weight the seat had been programmed for.

\section{Investigation}

On September 19, 2003, a fencing contractor and 3 laborers were building and repairing fence on a dairy farm. The 4 man crew had been building and repairing fence at the farm for several days. In the morning on the day of the incident, the contractor borrowed a skidsteer from the farmer to drive posts in the ground. The contractor owned and operated an identical skidsteer. Both the contractor and the decedent were knowledgeable and comfortable with operating the equipment. Neither had documented formal training on skidsteer operation.

Late that afternoon (a little after 4:00 PM), the farmer had requested the skidsteer be returned to the barn so that the late afternoon feeding could be done. The contractor instructed the decedent to return the skidsteer to the barn which entailed driving the machine approximately 200 yards through a pasture secured with a closed gate, then on to the barn lot.

The decedent proceeded to drive the skid-steer with the bucket in the up-right position to the gate. When he arrived at the gate, he left the bucket up in the air and exited the machine to open the gate. He was either entering the machine or exiting the machine when the bucket arms were activated which caused the bucket to descend and crush the victim between the bucket arms and the machine. The contractor heard the skidsteer idling for too long; then he and the crew noticed the skidsteer was still by the gate and had not moved. They ran to the skidsteer 200 yards away and found the decedent pinned inside the arms of the machine. He had been squeezed on the left side of his body with his right side near the controls of the machine and his right foot inside the machine near the controls. The bucket hit his chest, left arm and rib cage. The farmer noticed the situation and ran to the skidsteer to help remove the decedent from the machine. Emergency response services were immediately contacted. Upon arriving several minutes later and assessing the situation, they contacted the coroner. 
No one responding to the scene remembers if the gate was open or closed after the incident occurred. If the gate was closed, the accident occurred as he exited the machine; if the gate was open, it occurred as he entered the machine. This incident raises several unanswered questions regarding how the arms became activated. The skidsteer was programmed to only start if there was sufficient weight in the seat and the seatbelt was fastened. No one can remember if the seatbelt was fastened or not at the time of the accident. The coroner verified that the seatbelt worked (but did not know if it was fastened at the time of the fatal incident) and a weight limit had been programmed at the time of the accident. However, no one knew what the weight limit of the seat was set at; or if the limit set was below or above the weight of the decedent. To exit the machine, the bucket should be on the ground, the parking brake set and the machine turned off. Then the operator should then use a three-point system to exit: step-up out of the cab onto the top of the bucket; turn around and use the hand grips (one on each side of the machine); step down into the bucket; then turn around and step out of the bucket. It is possible the seatbelt had been improperly fastened with the bucket in the air. This would make exiting the cab more difficult and clumsy; the victim may have used one hand grip and used the seat for balance. This could apply enough pressure on the seat switch to activate the controls. If the victim was halfway in or out of the cab, his foot could have been on the control pedal and activated the bucket to descend.

\section{Cause of Death}

Cause of death is listed as due to mechanical asphyxiation secondary to blunt force injuries to the trunk.

\section{Recommendations and Discussions}

Recommendation No. 1: Employers should ensure that employees are adequately trained on proper operation of and safety mechanisms of material handling equipment.

The decedent had used the contractor's identical skidsteer and was familiar with its operation and safety features; however, the decedent did not have formal training on the skidsteer. When operating a skidsteer, operators should follow manufacturer's specifications. According to the National Institute of Occupational Safety and Health's publication 98-117, on safe skidsteer operation, it is important, when exiting/entering the cab of a skidsteer, to have the bucket in the downward position on the ground and to use three-point contact with the machine. There are several KY OSH regulations which pertain to training of employees that operate material handling equipment such as skidsteer loaders. They are: 1910.178(l) which states that employers shall ensure that the operator is competent to operate a powered industrial truck [material handling equipment] and has been trained by a competent individual; Employees will be trained in: 1910.178(l)(3)(i)(A) - "Operating instructions, warnings, and precautions for the types of material handling equipment the operator will be authorized to operate"; 1910.178(l)(3)(i)(C) - "Truck controls and instrumentation: where they are located, what they do and how they work"; 1910.178(l)(3)(i)(M) - "Any other operating instruction, warnings, or precautions listed in the operator's manual for the types of vehicle that the employee is being trained to operate"; 1926.602(a)(2)(i) - "Seat belts shall be provided on all equipment covered by this section and shall meet the requirements of the Society of Automotive Engineers, J386- 
1969, Seat Belts for Construction Equipment. Seat belts for agricultural and light industrial tractors shall meet the seat belt requirements of Society of Automotive Engineers J333a-1970, Operator Protection for Agricultural and Light Industrial Tractors.

Recommendation No. 2: Employers should have a written safety policy outlining safety practices, procedures and state the consequences of not following the company policies (1).

The company involved in this fatality did not have written safety procedures. Training should be provided with explanations of consequences if the program is not followed. For example, if safety protocol is not followed, the worker will be docked a day's pay. All training should be documented. Employees should be required to sign that they understand the safety and training program, and the enforcement and consequences for failure to follow safety instructions (1).

\section{Keywords}

Bucket

Three-point contact

Skidsteer

Machinery

\section{References}

(1) Kentucky FACE Report 03KY097

(2) DHHS (NIOSH) Publication No. 98-117

(3) Kentucky Occupational Safety \& Health Standards for General Industry

(4) Kentucky Occupational Safety \& Health Standards for the Construction Industry

\section{Acknowledgements}

Ky OSH Consultant

Coroner

Farmer

Kentucky Occupational Safety Officer

The Kentucky Fatality Assessment \& Control Evaluation Program (FACE) is funded by a grant from the Centers for Disease Control and the National Institute of Safety and Health. The purpose of FACE is to aid in the research and prevention of occupational fatalities by evaluating events leading to, during, and after a work related fatality. Recommendations are made to help employers and employees have a safer work environment. For more information about FACE and KIPRC, please visit our website at: www.kiprc.uky.edu 


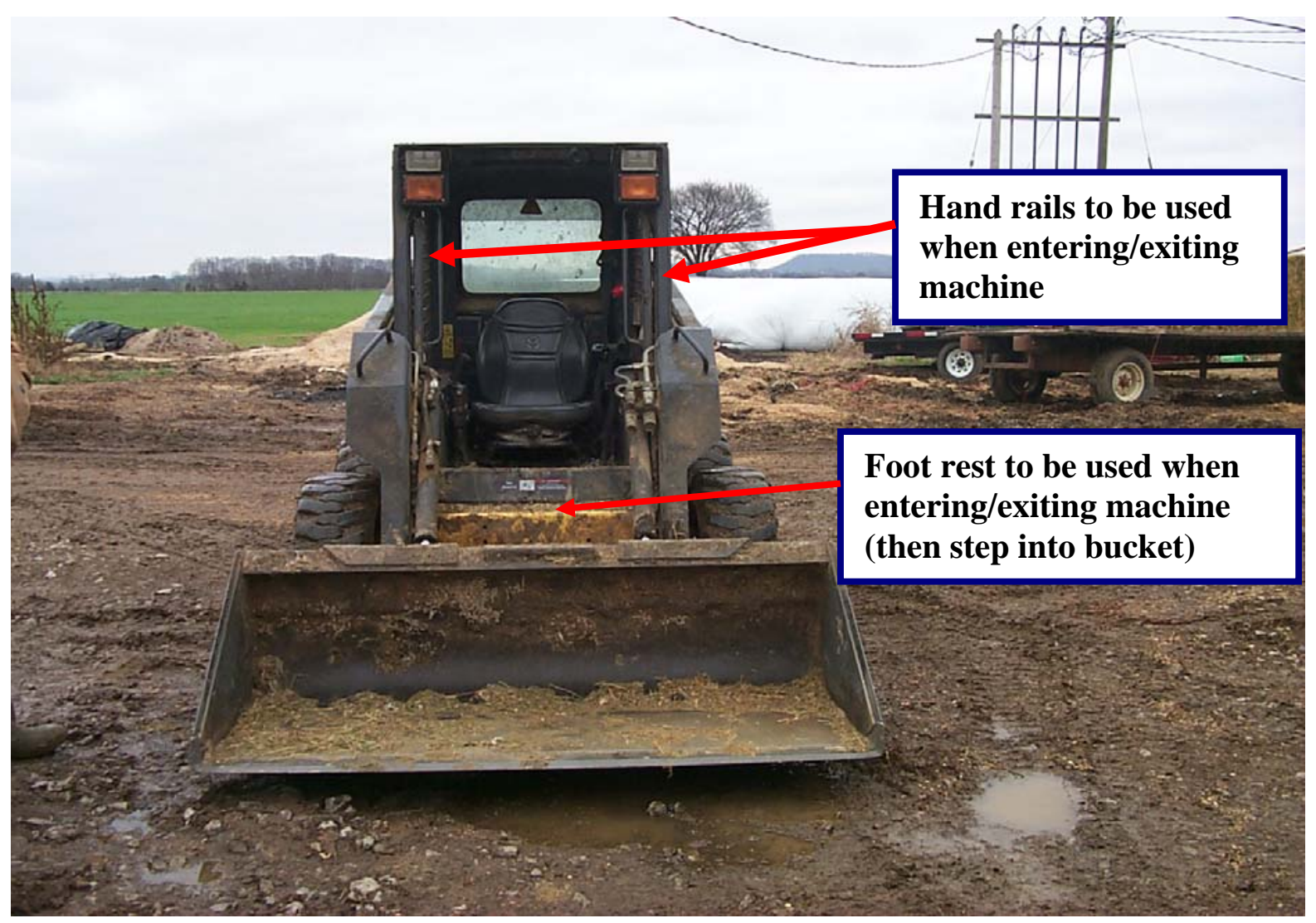

The operator should always have the bucket in the downward position, the parking brake set and the machine turned off and use three-point contact when entering or exiting a skidsteer. 


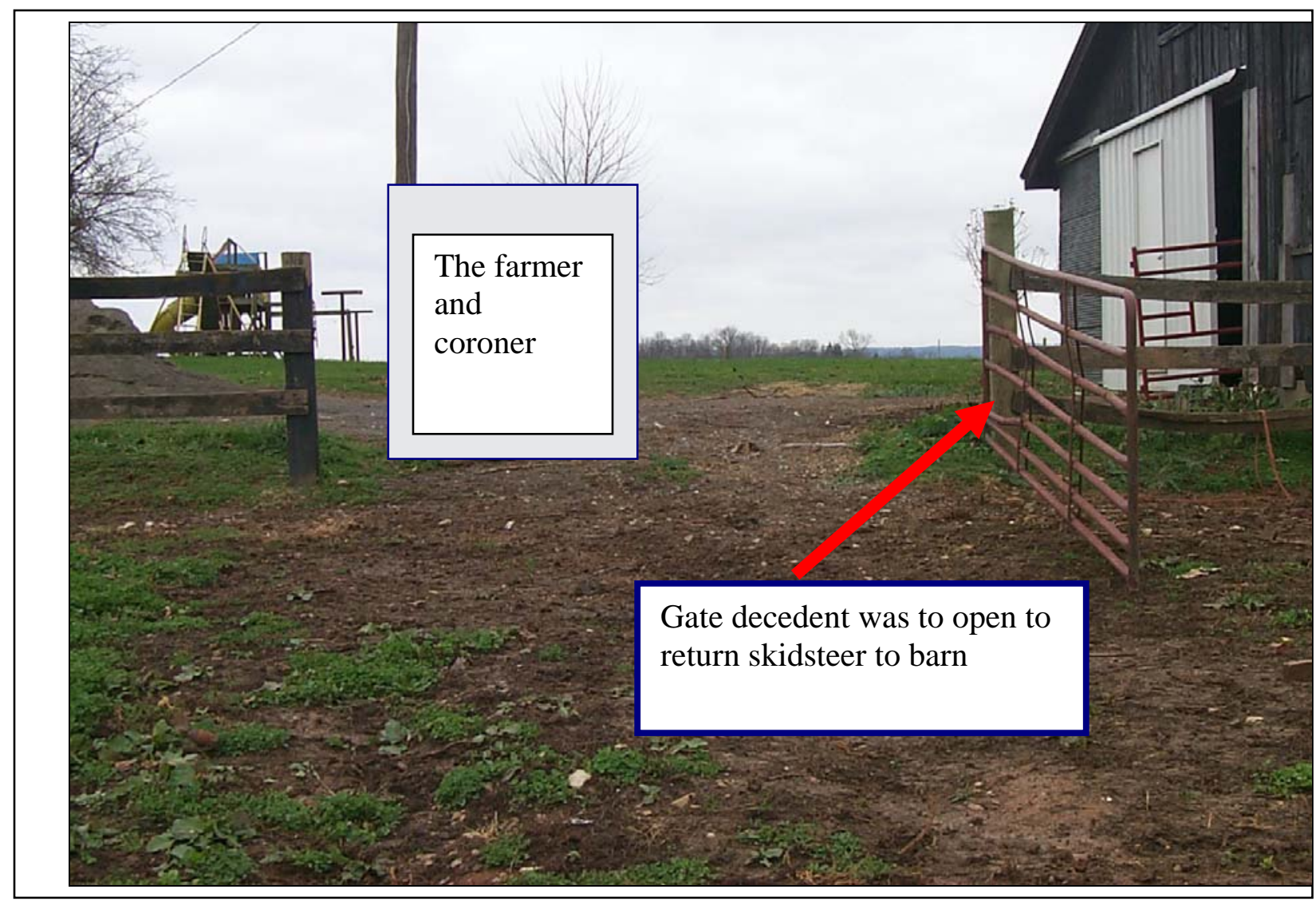

